\title{
REFLETINDO SOBRE A FORMAÇÃO E DESEMPENHO DO DOCENTE DE ENFERMAGEM
}

\author{
Virginia Visconde Brasil ${ }^{1}$, Celi Cristiane Pereira de Alencar ${ }^{2}$, Ivone Mucci ${ }^{3}$
}

\begin{abstract}
RESUMO: A discussão sobre o processo Ensino-aprendizagem sempre foi alvo de reflexões dentre aqueles que se preocupam com a qualidade do desenvolvimento do profissional. A qualidade do ensino na enfermagem vem sofrendo críticas nos últimos tempos. As escolas buscam formar profissionais com corpo de conhecimento científico, habilidades técnicas e atitudes que muitas vezes encontram-se desvinculadas da realidade dos locais de trabalho. No que se refere aos dispositivos legais que regem o ensino de enfermagem observamos que eles não são específicos com relação ao professor de nível superior, e na formação desse profissional enfermeiro não é dado enfoque para subsidiar uma possível atividade docente. Ao refletirmos sobre a prática de ensino de enfermagem, consideramos que são diversas as opções pedagógicas adotadas e a escolha de uma delas relaciona-se à finalidade que o docente dá ao seu trabalho, bem como às políticas adotadas pelas instituições de ensino e as características particulares de cada docente. A opção pedagógica adotada e praticada pelo docente tem influência na formação da consciência crítica dos alunos e em seus valores e hábitos componentes importantes para a construção de uma nova sociedade. Percebemos, no entanto, que os docentes de enfermagem parecem não estar suficientemente preparados para desenvolver nos alunos o pensamento crítico, uma vez que também não tiveram formação para tal, influenciando tanto em suas atividades teóricas como no campo clínico. Nesse contexto, buscou-se refletir: A formação didático-pedagógica contribui para melhorar o desempenho na prática de ensino? Ser bom enfermeiro significa que será bom professor de enfermagem?
\end{abstract}

DESCRITORES: Docente de Enfermagem; Ensino.

\section{THINKING ABOUT THE COMPETENCE AND PERFORMANCE OF THE NURSING FACULTY}

\begin{abstract}
: the discussion about the learning and teaching process was always in the discussion of those who care quality have been criticized. The teaching graduate professionals with a scientific knowledge, technical abilities an attributes that are sometimes not entailed with the work's reality. The legal concerns about nursing teaching are no specific about what kind of teachers is necessary for undergraduate level, and during graduation the student does not receive enough information to subsidize a possible teaching activity. When we think about nursing teaching we consider that are many pedagogical options adopted and its choice is related to the finality the teacher's gives to his work, as well as the school policy and each teacher's particular characteristics. The teacher's pedagogical option has influence on the students critical preparation and in their values and habits - important components to the construction of a new society. We perceive, however, that the nursing teachers seem not to be prepared to develop in the students the critical thinking, since they were not prepared for it the specific didatical and pedagogical preparation would contribute to a better teaching performance. To be a competent professional may not mean necessarily be a good nursing teacher.
\end{abstract}

DESCRIPTORS: Faculty; Nursing; Teaching.

\footnotetext{
${ }^{1}$ Enfermeira. Professora Auxiliar da Faculdade de Enfermagem e Nutrição da Universidade Federal de Goias. Mestranda da Escola de Enfermagem da Universidade de São Paulo-USP.

${ }^{2}$ Enfermeira de Saúde Pública da Secretaria Municipal de Saúde de Sã o Paulo. Mestranda da Escola de Enfermagem da USP.

${ }^{3}$ Enfermeira. Professora Assistênte da Universidade Cidade de São Paulo. Mestranda da Escola de Enfermagem da USP.
} 


\section{INTRODUÇÃO}

A discussão sobre o Processo Ensino-Aprendizagem sempre foi alvo de reflexões dentre aqueles que se preocupam com a qualidade do desenvolvimento do profissional. Entretanto, para atingir este objetivo, é necessário pensar antes nos formadores destes profissionais.

A compreensão da atual situação do ensino em enfermagem deveria implicar primeiro a revisão e observação da evolução histórica da enfermagem, para posterior reflexão sobre sua influência nos "formadores de formadores" da nossa profissão, pois as escolas conservam atitudes e posturas que refletem a prática de seus primórdios. Devemos relembrar quem foram os primeiros formadores, que objetivos tinham, pois todo acontecimento tem uma razão histórica de ser.

Os relatos sobre algum grupo organizado de trabalho em enfermagem datam da era cristã. $O$ cristianismo fez com que o número de pessoas que prestavam assistência aumentasse, como meio de expiação do pecado. Predominavam os ideais de fraternidade, de serviço, de caridade e de auto-sacrifício. $\mathrm{O}$ saber dessa prática expressava-se em simples procedimentos caseiros, como os cuidados domésticos prestados pela mulher (Deloughery, 1977).

Durante os séculos V e VI houve crescimento do número de hospitais. Até o século XVIII, eles eram essencialmente instituições de assistência aos pobres, e ao mesmo tempo de separação e exclusão, não tendo por objetivo a cura dos doentes (Focault, 1978).

O preparo exigido no século XVII para se aprender os rudimentos de enfermagem era que se soubesse ler e escrever, sendo de competência médica os esclarecimentos científicos necessários para essa prática. Em 1835, Robert Cook sugeriu um "Programa de Preparo de Enfermeiras" na Inglaterra, objetivando embasamento moral e relativo preparo técnico científico. Somente em 1860 foi fundada a $1^{\text {a }}$ Escola de Enfermagem no St. Thomas Hospital, sob orientação de Florence Nightingale (Paixão, 1960, Trivelato, 1993).

No Brasil, os trabalhos de Enfermagem iniciaram-se com os jesuítas. No final 1890 , foi criada a $1^{\text {a }}$ Escola de Enfermagem pelo Decreto ${ }^{\circ}$ 791, no Hospital Nacional de Alienados do Rio do Janeiro, que exigia para ingresso no curso apenas que o candidato soubesse ler, escrever e ter conhecimento de matemática elementar (Lanthier, 1983).

Em 1923, por razões econômicas, o Departamento Nacional de Saúde Pública (DNSP) convidou enfermeiras norte-americanas para organizarem no Rio de Janeiro a primeira escola nos moldes nightingalianos (EE Ana Néri - 1926), que exigia para ingresso no curso apenas o ginásio.

Com o desenvolvimento urbano e modernização dos hospitais surgiram novos cursos de enfermeiros e de auxiliares enfermagem.

Com esses dados históricos surgiram novos cursos de enfermagem no país, sendo criadas escolas para a formação de pessoal sempre esteve vinculada a outros motivos, que não à necessidade de se melhorar a assistência prestada à população ou à atuação de qualidade de um profissional.

Florence Nightngale destacou-se em momentos de dominação política econômica, reforçando a ideologia de que a enfermeira precisava ser disciplinada e obediente, sem crítica social. Kalisch, Kalisch (1975) afirmam que a enfermeira deveria ter um "treinamento rígido que desenvolvesse a responsabilidade, a obediência, a delicadeza, a submissão, a destreza no trabalho pesado, a lealdade, a passividade e a religiosidade". Esta opinião é reforçada por Waldow et al. (1995), ao afirmarem que a escola vem estimulando a submissão e a falta de autonomia profissional, pois aquilo que tem sido "preconizado como postura profissional, liderança, criatividade, participação, iniciativa e segurança emocional, na verdade subentende o estímulo à discrição, ao controle, à disciplina, à obediência, à docilidade e acriticidade que justificam e/ou reforçam a dominação - subordinação de gênero e de classe na área da saúde".

Alencar, Monteiro (1985) salientam que o ensino de enfermagem supervaloriza certas atitudes consideradas qualidades, e que os alunos devem incorporar em busca de um comportamento profissional pautado na disciplina, na obediência e em rígidos padrões éticos. Assim forma-se enfermeiros neutros, conformados, subservientes, orientados apenas para cuidados relacionados ao tratamento e conforto dos pacientes.

Posteriormente, os profissionais sentiram maior necessidade da busca de saber científico para fundamentar o ensino de enfermagem, estabelecendo assim a dimensão intelectual do trabalho e a valorização do homem como ser biológico e psicossocial. Surgiram então as teorias de enfermagem, "um corpo de conhecimentos específicos que daria à enfermagem o status da ciência" (Waldow et al., 1995).

Neste contexto, houve crescimento do número de escolas de graduação de enfermagem e o corpo docente passou a ser de enfermeiros, com a colaboração de profissionais correlatos. Os graduados, a cada ano, assumem a sua função educadora junto ao paciente, à comunidade e à equipe de enfermagem, e podem tornar-se futuros docentes. Essa postura requer contínua reflexão sobre os princípios orientadores que norteiam a formação de futuros profissionai9s, ou a forma como são orientados os integrantes da equipe de enfermagem, pois sua ação prática não é apenas pedagógica, e sim política, transformadora da sociedade em que vivem.

\section{O PROFESSOR DE ENFERMAGEM NO CONTEXTO NACIONAL}

Quando se fala nas crises que o Brasil vem enfrentando, o setor educação parece estar ocupando lugar de destaque, pela gravidade e constância de seus problemas. Tal "crise" tem suas características inerentes ao setor educacional, mas não deixa de sofrer os reflexos dos problemas enfrentados por vários outros setores, cujos resultados finais, com relação ao ensino, têm também repercussões na sociedade como um todo. A qualidade do ensino em geral, assim como no ensino 
da enfermagem, vem sendo muito criticada nos últimos tempos; a insatisfação, por parte dos professores e dos alunos, é notória (Waldow, 1989). São vários os aspectos que devem ser repensados no que se refere aos conteúdos, às práticas de ensino e outras atividades desenvolvidas.

Atualmente, o docente não tem somente a prática do ensino como atividade; são variadas as atividades burocráticoadministrativas desenvolvidas por ele, que competem com o tempo destinado ao ensino. Além disso, hoje, a docência de enfermagem faz parte de um processo na carreira universitária, em que a pesquisa passou a ser fundamental.

Outro aspecto importante que cumpre observar é que a realidade da academia, na qual são elaborados e transmitidos os conteúdos para os futuros profissionais, nem sempre condiz com os campos de trabalho oferecidos pelo mercado, reforçando um antigo problema dos enfermeiros relativo, muitas vezes, à dicotomia entre a teoria e a prática. As escolas, orientadas por filosofia própria, buscam formar um profissional, por ela concebido como ideal, com um corpo de conhecimento científicos, de habilidades técnicas e atitudes desvinculadas, muitas vezes, das situações que ele encontrará nos locais de trabalho.

A integração docente-assistencial tem sido apontada como uma das estratégias para articulação da escola com os serviços de assistência. Busca-se a identificação da realidade existente, como base para o planejamento e desenvolvimento de ações acadêmicas e assistenciais. A interação como pessoal da assistência propicia a incorporação, pelo aluno, de algumas atitudes e valores relacionados ao agir profissional (Ferreira, 1990).

Essas preocupações nos levam a questionar se estes profissionais estão alertados para a ampla função na área assistencial, administrativa, de assessoria, de pesquisa e de ensino, que a sociedade lhes outorga com o título de enfermeiros.

Sendo os enfermeiros responsáveis pela formação de pessoal de nível médio e superior, são eles preparados para exercer tal atividade?

A formação didático-pedagógica específica contribui para melhorar o desempenho na prática de ensino?

Buscamos no decorrer deste trabalho respostas a estas perguntas, que incomodam, quando se pensa sobre a dimensão do que é exigido de um profissional, que talvez não tenha sido suficientemente preparado para o que se espera dele.

\section{A FORMAÇÃO DO ENFERMEIRO DOCENTE}

Ao buscar os dispositivos legais que regem o ensino de enfermagem no $2^{\circ}$ e $3^{\circ}$ grau, observamos que eles não são específicos quanto ao profissional que seria professor para o nível superior, enquanto para o nível médio a legislação é bem explícita.

O Decreto-Lei $\mathrm{n}^{\circ}$ 27.426/49, que aprovou o Regulamento Básico para os cursos de enfermagem e Auxiliar de enfermagem, já estabeleceu qual profissional ministraria os cursos e respaldou as leis posteriores: para o nível superior “...professores contratados, inspetores, enfermeiros chefes dos hospitais, professores especializados...” (art.20); e “...no ensino das cadeiras não privativas...por professores e assistentes daqueles cursos ou por médicos especializados..." (art.21). Para o nível médio “...o ensino de Enfermagem Auxiliar somente poderá ser ministrado por enfermeiros..." (art.29) (Brasil, 1974a).

Atualmente, o Decreto-lei $n^{\circ} 94.406 / 87$, que rege o exercício da profissão, estabelece em seu art. $8^{\circ}$, que incumbe ao enfermeiro, não privativamente e sim como integrante da equipe de saúde "...participação em programas de educação sanitária..." e ainda "...participação nos programas de treinamento e aprimoramento de pessoal de saúde, particularmente nos programas de educação continuada..." (Brasil, 1987). Esse decreto vetou os itens que se referiam à participação privativa do enfermeiro na formação do pessoal de enfermagem constantes na lei 2.064/55, que regulava o exercício profissional e fazia referência ao magistério no ensino do enfermeiro e do auxiliar de enfermagem em seu artigo $3^{\circ}$ (Brasil, 1974b), mas como ela ainda não foi revogada, podemos usa-la para garantir que o ensino de enfermagem seja feito pelo enfermeiro (Dilly, Jesus, 1995).

O parecer CFE $n^{\circ} 292 / 62$ estabeleceu para os professores do nível médio a exigência de terem cursado licenciatura (Brasil, 1962). Sabemos, porém, que hoje, com o grande número de escolas de nível médio, e com o pequeno contingente de graduandos que optam por cursar licenciatura, este parecer nem sempre é respeitado pelas escolas.

Recentemente a Portaria 1721/94 fixou os mínimos de conteúdo e duração do curso de graduação de enfermagem (Brasil, 1994), contudo não contemplou os requisitos necessários ao exercício do magistério, ou seja, o enfermeiro continua legalmente sem a instrumentação necessária para o exercício do ensino.

Segundo Gatti (1992) a formação de professores no Brasil está sendo feita, na maior parte das vezes, pelas instituições isoladas de ensino superior, não pelas universidades, e o ensino ocorre em condições precárias com pessoal de qualidade questionável. Há certa inércia nas universidades com relação ao repensar as licenciaturas, mesmo naqueles cursos cujo corpo discente tem como objetivo o ensino. As instituições de ensino superior são responsáveis pela formação dos professores, assim como pela sua educação continuada. No entanto, não há enfoque específico para subsidiar uma possível atividade docente. O profissional vêse numa situação de difícil discernimento: é especialista na área ou um professor?

Nesse contexto, questiona-se se é suficiente ser profissional competente para ser bom professor. Ser excelente enfermeiro significa que será bom professor de enfermagem?

Ser professor, ou ser profissional de qualquer disciplina parece ser algo construído, não simplesmente dom, intuição inata; para ensinar é preciso aprender a fazê-lo. 


\section{FORMAÇÃO X PRÁTICA}

São diversas as maneiras pelas quais o docente exerce sua prática no processo de ensino. Atualmente, contamos com a colaboração de vários pedagogos no sentido de classificarem ou subdividirem essas práticas conforme suas principais características.

A escolha pelo docente das técnicas de ensino e avaliação, ou seja, sua opção pedagógica, encontra-se relacionada à finalidade que este dá ao seu trabalho. Porém nem sempre aquela teoria de ensino em que o professor realmente acredita, é a adotada para direcionar sua prática, pois a realidade, muitas vezes, não oferece condições para a sua aplicabilidade (Libâneo, 1982).

Ao mesmo tempo, a opção pedagógica, adotada e praticada pelo docente, pode fortalecer ou debilitar o desenvolvimento da consciência crítica dos alunos e os valores e hábitos de criatividade, solidariedade e participação que são componentes importantes para construção de uma nova sociedade (Bordenave, 1989).

Talvez, se tentarmos identificar uma tendência na prática docente da enfermagem, poderemos inferir que aquela de características conservadoras seja ainda a predominante, principalmente dentro das escolas mais antigas, onde o modelo adotado foi mantido até os dias de hoje. Entretanto, em pesquisa desenvolvida por Saupe (1993), foram verificadas transformações com relação ao professor de enfermagem; há uma expressão já significativa de professores críticos, em contradição com os moldes rígidos, com prática pedagógica democrática e participativa, considerando-se a enfermagem uma profissão historicamente determinada, numa sociedade em constante transformação.

Segundo Cunha (1989), quando o professor faz uma reflexão sobre si, seus valores, crenças e práticas pedagógicas, percebe modificações ao longo de sua trajetória profissional e, "com relação à escola, é ao mesmo tempo determinante e determinado".

O que se encontra vinculado à escolha da prática que o docente utiliza, está relacionado às políticas adotadas pelas instituições de ensino, mas também possui vínculo muito estreito com as características particulares inerentes a cada docente: cria-se uma situação que precisa ser estudada, identificando as transformações necessárias a cada momento.

\section{A PRÁTICA DO DOCENTE}

Os docentes de enfermagem têm diante da sociedade a responsabilidade de formar profissionais críticos, analíticos e com competência para prestar uma assistência de enfermagem de qualidade. Para isso devem rever constantemente sua atuação e conhecimento com relação ao ensino.

$\mathrm{O}$ processo ensino-aprendizagem deve ser contextualizado no momento histórico, político, econômico e social de um grupo. Ele é dinâmico, exige do docente constante reflexão e avaliação de postura.
Embora seja o professor o responsável pela formação geral do aluno e propicie seu desenvolvimento crítico, percebemos que a maioria dos docentes de enfermagem não estão suficientemente preparados para oferecer aos alunos um ambiente que favoreça o desenvolvimento do pensamento crítico, uma vez que os próprios docentes não tiveram essa formação nos bancos acadêmicos.

Trivelato (1993) reforça que "o professor não conseguirá promover efetiva mudança na sua didática, se não se tiver libertado da crença nas suas idéias de senso comum sobre o ensino, centrados no poder da transmissão verbal e no direcionamento das atividades tendentes a minimizar o erro".

O professor deve saber conduzir as experiências dos estudantes também no corpo clínico, favorecendo o desenvolvimento da reflexão de sua ação. Todavia, como não teve preparo para tanto, e a literatura, por ser escassa, lhe oferece pouca ajuda, acaba por se basear na vivência pessoa ou na experiência de seus colegas, tornando-se autodidata.

Na formação do profissional de enfermagem, o ensino teórico íntima relação com a prática. No processo ensinoaprendizagem, a prática deve confirmar a teoria; no entanto isto não é vivência constante na enfermagem. Essa dicotomia está presente ao observarmos que o enfermeiro é preparado para o planejamento e execução do cuidado ao paciente; porém as instituições de saúde exigem, muitas vezes, ações ligadas principalmente à gerência de serviços. Para Dilly, Jesus (1995), as escolas têm responsabilidade de selecionar as disciplinas do curso e fazer com que os conhecimentos e comportamentos finais sejam condizentes com o papel do enfermeiro na sociedade.

A ênfase no ensino e na pesquisa tem ficado, na maioria das escolas, a cargo dos cursos de Pós-graduação criados no esforço de se capacitar os docentes para essas atividades. Observa-se, porém, que o fio condutor desses cursos se direciona mais para a pesquisa. Os docentes que adquirem formação para o ensino foram buscá-la por esforço próprio ou diretamente na área específica da educação.

\section{CONSIDERAÇÕES FINAIS}

Ao observarmos a prática do ensino na sociedade brasileira, percebemos que esta vem sofrendo descaso por parte do governo em meio a tantas crises, e particularmente, a educação ocupa lugar pouco privilegiado em face de qualquer tipo de investimento.

Isso, sem dúvida, infunde nos professores o desencanto, o desestímulo e o descompromisso para com o ensino.

Como conclusões de uma pesquisa desenvolvida por Cunha (1989), o conceito de "bom professor" é valorativo com relação a um tempo e um lugar, e é ideológico, por representar a idéia que a sociedade constrói sobre ele.

$\mathrm{O}$ docente enfermeiro tem diante de si grande responsabilidade, pois ao formar o profissional que será líder a planejador da profissão, está formando não só enfermeiros, mas preparando os responsáveis pela evolução da própria 
enfermagem. Está em jogo o progresso da profissão (Friedlander, 1995).

Atualmente, na enfermagem, apesar de fazermos parte do setor educação com seus problemas gerais, e de estarmos vivenciando momentos de insatisfação e objetivando transformações com relação ao ensino da profissão, podemos dizer, contrariamente à situação do passado, que a formação do profissional está sendo vinculada à preocupação com a qualidade da assistência prestada à população.

Porém, mesmo com essa visão do objetivo final do processo de formação do profissional enfermeiro, questionamos a inexistência de normas legais inerentes à sua capacitação para exercer atividades de ensino, ou seja, a "formação de formadores".

O enfermeiro tem formação direcionada basicamente para o conhecimento relacionado à sua prática assistencial, com pouca ênfase para outras possíveis atividades, como a docente, fazendo que, por vezes, esse profissional não esteja conscientizado das outras funções que lhe são atribuídas pela sociedade, com o título que esta lhe outorga.

É valido dizer que um profissional competente não pode não ser necessariamente "bom" professor, pois mesmo esta denominação requer análise muito ampla. Uma formação pedagógica específica iria contribuir muito para a prática do decente, mas apenas isso não significa que teríamos professores capacitados, com adequado desempenho de suas atividades.

Acreditamos que uma grande parcela deste contexto está relacionada à pessoa em si, suas características, sua história, sua vivencia. A articulação desses fatores, com o ambiente, com a influência de suas características sócio-políticoeconômicas, num momento vai formar.

Paralelamente às questões relacionadas à formação do docente de enfermagem, é imprescindível a abordagem da relação entre a teoria e a prática profissional, pos se observa uma dicotomia, uma vez que a realidade da prática nem sempre corresponde ao que foi ensinado.

O profissional de enfermeiro é um educador permanente e, no seu dia-a-dia, enfrenta situações formais e informais de ensino, necessitando assim de educação continuada que lhe dê o suporte para enfrentá-las, e favoreça o desenvolvimento de suas possibilidades individuais.

Assim haverá sempre a necessidade de transformação, pois uma sociedade não inerte, pronta, mas sim faz parte de um processo dinâmico cuja realidade precisa ser constantemente identificada para subsidiar novos planejamentos.

\section{REFERÊNCIAS}

1. ALENCAR, R.C.G., MONTEIRO. B.N. Sistema de avaliação de alunos de enfermagem em unidade de recuperação e cuidado intensivo - uma contribuição. In: CONGRESSO BRASILEIRO DE ENF, 37., 1985, Recife. Anais... Recife: Associação Brasileira de Enfermagem - Sessão Pernambuco; 1985. p. 47-63.

2. BORDENAVE, J.E.D. Alguns fatores pedagógicos. In: BRASIL, Ministério da Saúde. Secretaria da Modernização Administrativa
Recursos Humanos. Capacitação pedagógica para instrutor/supervisor área da saúde. Brasília, 1989, p. 19-26.

3. BRASIL. Parecer CFE 292/62, que fixa a parte pedagógica dos currículos mínimos relativos aos cursos de licenciatura. Documenta. Brasília, n. 10, p. 95-101, 1962.

4. Decreto $n^{\circ}$. 27.496, de 14 de novembro de 1949. Regulamenta a Lei $\mathrm{n}^{\circ} .775$ de 06 de outubro de 1949 que aprova o regulamento básico para os cursos de enfermagem e auxiliar de enfermagem. In: BRASIL, Enfermagem: legislação e assuntos correlatos. 3. ed., Rio de Janeiro, 1997b. v.2, p. 217-222.

5 . Lei $\mathrm{n}^{\circ}$. 2.064/55, regulamentada pelo Decreto 50.087/61 aprovando o exercício da enfermagem e suas funções auxiliares no território nacional. In: BRASIL, Ministério da Saúde, Fundação Serviços de Saúde Pública. Enfermagem: legislação e assuntos correlatos. 3 ed., Rio de Janeiro, 1947b. v.2, p. 217-222.

$6 . \quad$ Decreto $\mathrm{n}^{\circ} .94 .406$ de 08 de junho de 1987, que regulamenta a Lei ${ }^{\circ}$. 7.498 de 25 de junho de 1986. Dispõe sobre a regulamentação do exercício da enfermagem e dá outras providências. Documenta Brasília, n. 319, p. 157-160, 1987.

7. $\quad$ Portaria $\mathrm{n}^{\circ} .1 .721$ de 15 de dezembro de 1994. Dispõe sobre os mínimos de conteúdo do curso de graduação de enfermagem. Diário Oficial da República Federativa do Brasil, Brasília, v132, n. 238, p. 19801-19802, 16 dez. 1994. Sessão 1.

8. CUNHA, M.I. O bom professor e sua prática. Campinas: papirus, 1989.

9. DELOUGHERY, G.L. History and trends of professional nursing. 8. ed., St Louis: C.V.Mosby, 1977.

10. DILLY, C.M.L., Jesus, M.C.P. de. Processo educativo em enfermagem: das concepções pedagógicas à prática profissional. São Paulo: Robe, 1995.

11. FERREIRA, N.M.L.A. Sistematização da assistência de enfermagem - importância para a profissão e responsabilidade no preparo do enfermeiro. Acta Paulista, São Paulo, v. 3, n. 3, p. 79-84, set. 1990.

12. FOUCAULT, M. Incorporación del hospital en la tecnologia moderna. In: Medicina y historia. Washington: OPS, 1978.

13. FRIEDLANDER, M.R. A formação do enfermeiro nas próximas décadas. Âmbito Hospitalar, São Paulo, v. 7, n.78, p. 57-61, set. 1995.

14. GATTI, B.A.A formação dos docentes: o conforto necessário-professor $\mathrm{X}$ academia. Cadernos de Pesquisa, São Paulo, n. 81, p. 70-74, maio 1992.

15. KALISH, B., KALISH, P. Slaves, servants or saints. Nursing Forum, Philadelphia, v. 8, n, 3, p.223-263, 1975.

16. LANTHIER, M.G.C. O professor de enfermagem: atuação em campo clínico. Salvador, 1983. Dissertação (Mestrado) - Universidade Federal Bahia.

17. LIBÂNEO, J.C. Tendências pedagógicas na prática escolar. Revista da Andes, Brasília, n. 6, p. 11-19, 1982.

18. PAIXÃO, W. Páginas de história da enfermagem. 2. ed., Rio de Janeiro: Bruno Buccini, 1960.

19. SAUPE, R. O professor de enfermagem - a transformação possível. Revista da Escola de Enfermagem da USP, São Paulo, v. 27, n. 1, p. 151-160. abr. 1993.

20. TRIVELATO, S.L.F. Ciência, tecnologia e sociedade - mudanças curriculares e formação de professores. São Paulo, 1993. Tese (Doutorado) - Faculdade de Educação, Universidade de São Paulo.

21. WALDOW, V.R. Reflexão sobre o ensino de enfermagem. Revista Gaúcha de Enfermagem, Porto Alegre, v. 10, n. 2, p. 41-44, jul. 1989.

23. WALDOW, V.R., LOPES, M.A.M., MEYER D.E. Maneiras de cuidar, maneiras de ensinar: a enfermagem entre a escola e a prática profissional. Porto Alegre: Artes Médicas, 1995. p. 76-77. 